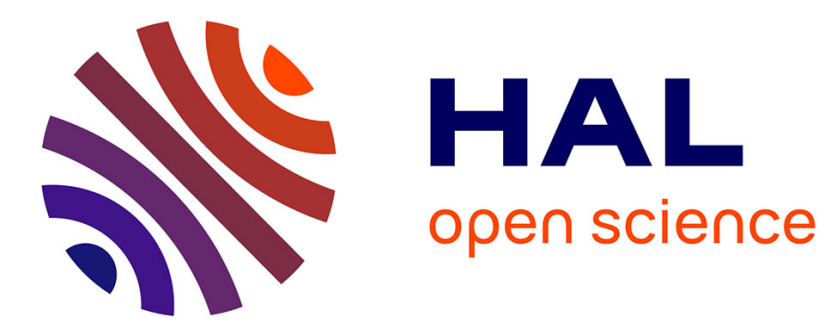

\title{
Dégâts provoqués par les campagnols à de jeunes plantations et moyens de dératisation utilisés
}

\author{
Jean Prax
}

\section{To cite this version:}

Jean Prax. Dégâts provoqués par les campagnols à de jeunes plantations et moyens de dératisation utilisés. Revue forestière française, 1949, 6, pp.263-266. 10.4267/2042/27969 . hal-03380053

\section{HAL Id: hal-03380053 \\ https://hal.science/hal-03380053}

Submitted on 15 Oct 2021

HAL is a multi-disciplinary open access archive for the deposit and dissemination of scientific research documents, whether they are published or not. The documents may come from teaching and research institutions in France or abroad, or from public or private research centers.
L'archive ouverte pluridisciplinaire HAL, est destinée au dépôt et à la diffusion de documents scientifiques de niveau recherche, publiés ou non, émanant des établissements d'enseignement et de recherche français ou étrangers, des laboratoires publics ou privés. 


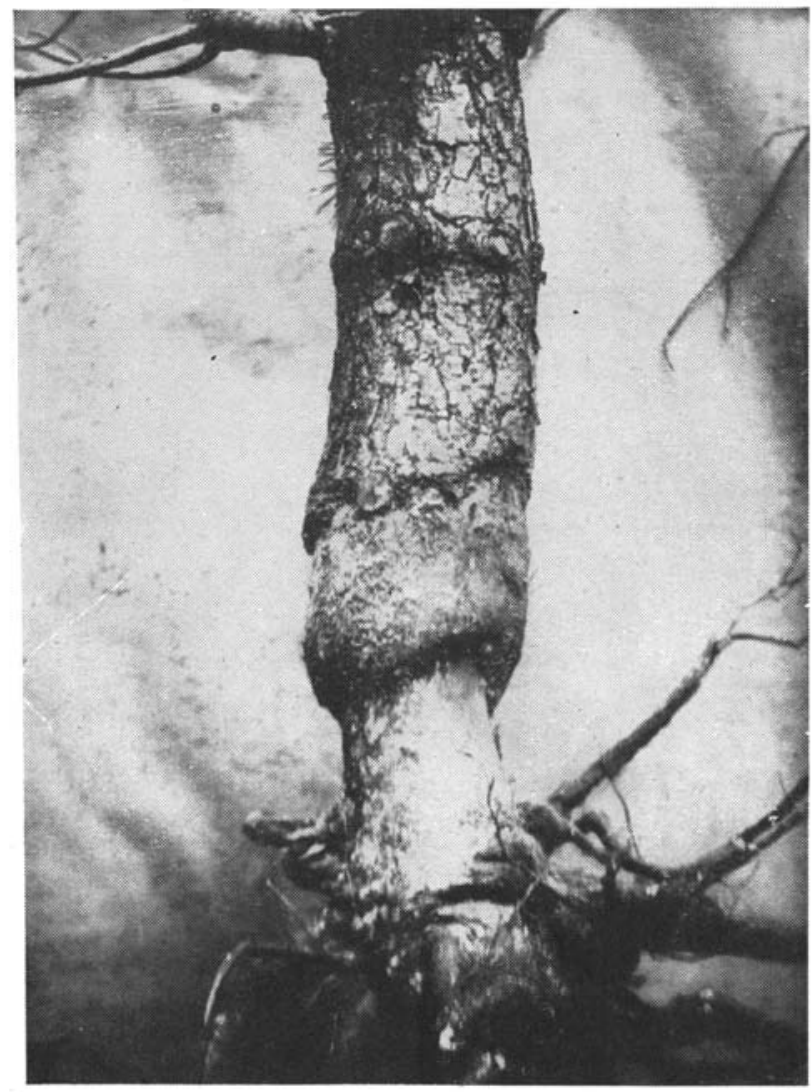

Annélation circulaire profonde provoquée en dessous du collet par les campagnols sur un pin sylvestre âgé de Io ans.

La blessure a entrainé le dépérissement puis la mort du sujet.

(Série domaniale de reboisement de La Salvetat-sur-Agout). 


\section{DÉGATS \\ PROVOQUÉS PAR LES CAMPAGNOLS \\ A DE JEUNES PLANTATIONS \\ et moyens de dératisation utilisés}

Indice bibliographique: $\mathbf{1 3 . 2 2 . 5 3 : 4 5}$

Dans toute la France, de graves dégâts de rongeurs ont été constatés au cours de l'hiver 1948-49 et du printemps suivant. M. l'Inspecteur PRAX donne d'intéressantes précisions sur leurs modalités et sur les traitements qui lui ont donné de bons résultats.

Dans les environs de Nancy, les dommages causés aux jeunes plantations et aux semis en pépinière étaient tout à fait du même ordre: les Sapins ont été très gravement touchés, mais aussi les Mélèzes, les Chamaecyparis et parmi la végétation spontanée le Charme, dont de très nombreuses cépées ont été écorcées et tuées.

$\mathrm{Si}$ les cultivateurs ont fréquemment l'occasion de déplorer les ravagés provoqués dans les cultures par la pullulation des mulots et campagnols, les forestiers n'ont eu, à ma connaissance, que fort rarement à se plaindre de ces rongeurs, mis à part bien entendu le tribut plus ou moins important prélevé annuellement sur les graines semées à demeure ou en pépinière.

Cette année, par contre, nous avons eu la désagréable surprise de constater des dégâts extrêmement importants causés par les campagnols aux plantations réalisées au cours de la saison 1948-1949 dans la haute vallée de l'Agoût, à l'extrémité occidentale des Cévennes méridionales.

Les longues périodes de sécheresse que nous traversons depuis plusieurs années sont, à n'en pas douter, à l'origine de la pullulation de ces petits animaux, dont les portées ont pu se développer sans avoir à souffrir, à l'intérieur des galeries, des pluies abondantes ou de l'eau de fonte des neiges.

Depuis quelques années, notre attention avait toutefois été attirée sur ces rongeurs par la constatation dans les parcelles plantées en Pin Sylvestre, du dépérissement et de la mort sur pied de nombreux arbres âgés de Io à I 5 ans. Un examen sommaire des sujets atteints avait permis d'attribuer cette mortalité à une annélation 
circulaire profonde pénétrant jusqu'au bois provoquée par les campagnols un peu au-dessous du collet, point correspondant au débouché des galeries autour du pied de l'arbre. (Voir cliché).

Mais il ne s'agissait là que de dégâts de faible importance eu égard à ceux constatés dans les plantations effectuées au cours de la saison I948-I949.

Ces travaux de boisement ont intéressé, dans les séries domaniales de La Salvetat-sur-Agout et Cambon, 200 hectares de terrains à une altitude moyenne de $\mathrm{r} .000$ mètres, couverts en général d'une végétation touffue de genêt à balais, fougère aigle et callune.

Il est probable que ces petits animaux ont trouvé, à l'intérieur et à l'abri de cette végétation dense qui les protégeait des rapaces et facilitait leurs déplacements, un milieu particulièrement favorable à leur développement, car dans les places à sol nu ou peu embroussaillé leur action a été nulle.

Parmi les plants de résineux, le sapin pectiné a été de beaucoup l'essence la plus touchée, dans une proportion atteignant souvent $8 a \%$ des sujets, dont une bonne partie doit être considérée comme perdue. Les ravages sont surtout importants dans certaines taches couvertes de touffes épaisses de genêt à balais. L'épicéa a également souffert, mais à un degré moindre que le sapin. Quant aux jeunes plants de Pin Sylvestre et de Pin Laricio de Corse, on peut les considérer comme indemnes.

Le processus de l'attaque est le suivant: l'animal commence par ronger les bourgeons terminaux, puis les aiguilles et enfin, si leur section est suffisamment petite (épicéa), l'axe des rameaux latéraux. Finalement, il ne reste sur pied que le squelette du plant, dépouillé de toutes ses parties vertes. Contrairement à ce qui se produit pour les feuillus, l'écorce de la tige ou des rameaux lignifiés n'est pas touchée.

Les deux essences feuillues utilisées (Hêtre et Chêne rouge d'Amérique) ont également souffert, en particulier les jeunes plants de hêtre de 2 ans. Ici, les campagnols ont rongé l'écorce sur une hauteur de 5 à 6 centimètres au-dessus du collet. Fréquemment même les plants ont été sectionnés raz terre.

Les déjections abondantes trouvées autour des plants ne laissent d'ailleurs aucun doute sur la nature des agents responsables de ces dégâts qui ne peuvent être confondus avec des dégâts de lapin. Ce dernier est en outre à peu près inexistant dans les terrains en cause.

M. le Professeur Delmas, de l'Ecole Nationale d'Agriculture de Montpellier a identifié parmi les sujets capturés sur place les espèces suivantes:

- Campagnol (Microtus Arvalis) espèce qui parait la plus abondante dans les terrains infestés.

- Mulot (Apodemus Sylvaticus). 


\section{Moyens de lutte utilisés. - RÉsultats}

Les deux procédés de lutte suivants ont été mis en œuvre sur les indications du Service Régional de la Protection des Végétaux dont l'aide nous a été particulièrement précieuse:

I $^{\circ}$ Virus Pasteur. - Employé sur 50 hectares dans la Série de La Salvetat. Le terrain à traiter étant couvert d'une végétation trop dense pour permettre l'épandage du grain imprégné de virus au trou, on a utilisé la méthode des abris-pièges. Ces derniers disposés en quinconce et distants l'un de l'autre de 80 mètres sont constitués par une fosse profonde de quelques centimètres de o m. 50 de côté. La fosse est recouverte avec des broussailles de façon à constituer un abri clos où les rongeurs se sentent en sécurité, à l'abri de la lumière.

Trois à quatre appâtages au moyen d'avoine aplatie ont été réalisés à quelques jours de distance et suivis de l'épandage d'avoine imprégnée de virus.

Les résultats de ce traitement ont été incertains et difficiles à constater.

Le virus Pasteur, culture de germes microbiens, est en effet sensible aux rayons solaires, de sorte que l'opération doit être réalisée par temps couvert ou à la tombée de la nuit. Il semble d'autre part que son action ne se prolonge pas au delà des vingt-quatre heures qui suivent l'emploi, ce qui en limite notablement l'efficacité.

$2^{\circ}$ Appâts empoisonnés au phosphure de zinc en émulsion. Les considérations ci-dessus nous ont incité, sur les conseils du Service de la Protection des Végétaux, à essayer un nouveau procédé d'emploi du phosphure de zinc qui aurait été utilisé pour la première fois en Angleterre au cours de la dernière guerre.

A vrai dire, ce produit est depuis longtemps employé pour la dératisation. Mais, mélangé à l'état pur au grain pour la confection d'appâts empoisonnés, il a l'inconvénient de se décomposer assez rapidement avec production d'hydrogène phosphoré. Ce phénomène entraîne des inconvénients pour la préparation des appâts en raison du gaz nocif dégagé et surtout réduit à quelques jours l'efficacité du produit.

Par contre, en émulsion dans l'huile de vaseline neutre, la décomposition du phosphure se trouve notablement ralentie et l'action des appâts dure certainement pendant dix à quinze jours.

Le traitement a porté sur I50 hectares au moyen d'avoine préparée suivant le dosage ci-dessous:

- Grain : Ioo kg.

- Huile de vaseline neutre: I litre.

- Phosphure de zinc: o kg 600 à o $\mathrm{kg} 900$.

Le phosphure est d'abord mẹlangé à l'huile et la mixture ạinsi 
obtenue brassée longuement avec l'avoine de façon à obtenir une imprégnation homogène (I).

L'épandage n'étant pas possible au trou ou dans les galeries pour les raisons exposées plus haut, l'appât a été répandu à raison d'une pincée déposée au moyen d'une cuiller à proximité de chaque plant sur la surface décapée au moment de la plantation. La quantité de grain nécessaire à l'hectare est de l'ordre de I2 kilogs.

Les dégâts ont été stoppés quelques jours après l'épandage et on peut dire que les résultats obtenus par ce procédé ont été pleinnement satisfaisants. Bien qu'il soit difficile de se rendre compte exactement des effets du poison, les rats s'enfonçant sous terre avant de mourir, il est permis de penser, d'après le nombre de cadavres découverts à l'occasion de l'ouverture d'une allée garde feu (jusqu'à 50 et plus à l'are) que la presque totalité de la population existante au moment du traitement a été détruite. Il reste, il est vrai, le danger d'une réinfestation provenant des terrain $\mathrm{S}$ agricoles ou forestiers voisins non traités.

La pullulation des campagnols étant signalée un peu partout en France, nous avons cru utile d'attirer par ces quelques lignes l'attention des lecteurs de la Revue sur les dangers susceptibles d'en résulter pour nos plantations (2).

Il serait regrettable, en effet, que les travaux réalisés en ce moment grâce au Fonds Forestier National aient à souffrir de ces rongeurs.

Le procédé de destruction au Phosphure que nous avons utilisé est par ailleurs susceptible de rendre service soit dans les pépinières forestières infestées par ces rongeurs, soit pour assurer aux semis à demeure de graines forestières le maximum de chances de succès.

Là où l'on redoute la destruction des graines par les rongeurs ou les oiseaux, ce qui est le cas général, il semble possible de réduire les pertes en enrobant la semence avec le mélange Phosphure-huile qui n'a aucun effet nuisible sur la faculté germinative.

Béziers, le I6 juin 1949.

\section{Jean Prax.}

(I) Le Phosphure de zinc figurant au Tableau $\mathrm{A}$ annexé au décret du I4 septembre I9I6 réglementant le commerce et l'usage des substances vénéneuses, la préparation des appâts empoisonnés par ce moyen doit être effectuée sous la responsabilité d'un pharmacien diplômé.

De plus, il paraît préférable, si le traitement doit intéresser une surface importante, d'obtenir une autorisation d'emploi par arrêté ministériel pris en application de l'article II de l'ordonnance du 2 novembre 1945 organisant la protection des végétaux ou, en cas d'urgence, par arrêté préfectoral.

(2) Des dégâts analogues à ceux décrits ci-dessus nous ont été signalés sur des plantations de Pin Noir d'Autriche dans le département du Gers, avec un maximum de $30 \%$ de plants atteints. 